\title{
El principio de autonomía e independencia. Consecuencias jurídicas y económicas derivadas de su aplicación en Costa Rica
}

(The principle of autonomy and independence. Legal and economic consequences arising from its application in Costa Rica)

\author{
Roxana Sánchez Boza ${ }^{1}$ \\ Universidad Nacional de San José de Costa Rica (Costa Rica)
}

Sumario: Antecedentes del principio de autonomía e independencia de las cooperativas, en el cooperativismo mundial y en Costa Rica. 1. Valor, respeto y modificaciones a la ejecución de los derechos y deberes derivados del principio en la perspectiva de algunos y algunas cooperativistas, a través de entrevistas. Perfiles de los entrevistados y entrevistadas. 2. Límites a la autonomía e independencia de las cooperativas según giro comercial o su incursión en la ejecución de algunos servicios públicos. 2.1. Cooperativas de caña de azúcar y obligación de compra a un productor no asociado. 2.2. Participación de personas jurídicas como asociadas de cooperativas. Límites a la autonomía: incursión en otro tipo de negocios, compra de sociedad mercantil. 2.3. Electrificación como servicio público prestado por cooperativas de electrificación rural y su posibilidad de emitir títulos valores para ser captados por terceros. 2.4. Participación de entes públicos: convenios de gestión de servicios de salud de la CCSS y cooperativas. 2.4.1. Convenios sujetos a la organización de la CCSS. Las juntas de salud y director médico del centro de salud. 2.5. Límites del INFOCOOP: deber de abstención en la toma de decisiones de las cooperativas. Posición no vinculante de sus criterios. 2.6. Nulidad de asambleas por control de legalidad declarada por el ministerio de trabajo y seguridad social. 2.7. Participaciones asociativas del INFOCOOP y entes cooperativos. 3. Restricciones al principio de autonomía cooperativa por leyes posteriores e invasión de competencias propias de las cooperativas de intermediación financiera a través normas de rango inferior. El caso de del reglamento de gobierno corporativo-SUGEF 16-16. 4. Conclusiones generales. 5. Glosario. 6. Bibliografía. 7. Anexo.

1 E-mail: metanoia500@yahoo.es 
Summary: Antecedents of the principle of autonomy and independence of cooperatives, in global cooperativism and in Costa Rica. 1. Value, respect and modifications to the execution of the rights and duties derived from the principle in the perspective of some cooperativists, through interviews. Profiles of the interviewed. 2. Limits to the autonomy and independence of the cooperatives according to the business line or their incursion in the execution of some public services. 2.1. Sugarcane cooperatives and purchase obligation to a nonassociated producer. 2.2. Participation of legal entities as cooperative members. Limits to autonomy: incursion in another type of business, purchase of mercantile society. 2.3. Electrification as a public service provided by rural electrification cooperatives and their ability to issue securities to be captured by third parties. 2.4. Participation of public entities: agreements for the management of health services of the CCSS and cooperatives. 2.4.1. Agreements subject to the organization of the CCSS. The health boards and medical director of the health center. 2.5. Associative participations of INFOCOOP and cooperative entities. 2.5.1. Limits of the INFOCOOP: duty of abstention in the decision making of the cooperatives. Non-binding position of your criteria. 2.6. Nullity of assemblies for control of legality declared by the Ministry of Labor and Social Security. 2.7. Associative participations of INFOCOOP and cooperative entities. 3. Restrictions to the principle of cooperative autonomy by subsequent laws and invasion of own competences of the financial intermediation cooperatives through lower rank norms. The case of the corporate governance regulation-SUGEF 16-16. 4. General conclusions. 5. Glossary. 6. Bibliography. 7. Annexe.

Resumen: El Principio de autonomía y independencia de las cooperativas fue recuperado y analizado en 1995, cuando los analistas y estudiosos de la Alianza Cooperativa Internacional decidieron revisar nuevamente los Principios cooperativos, lo cual dio como resultado la incorporación de ese principio en la lista que circulaba hasta ese momento. Cada país tiene una forma diferente de asumir los conceptos de autonomía e independencia de los entes cooperativos, en Costa Rica existen múltiples manifestaciones de entes públicos que analizan su aplicación práctica y conforme las cooperativas han visto oportunidades de negocios, han ido dejando parte de su defensa por la autonomía de sus decisiones, con el fin de cumplir con el objeto social definido como la logro del bienestar económico y social de sus asociados y de la comunidad en que se desarrollan.

Palabras clave: cooperativas; autonomía; independencia; alianzas públicas y privadas.

Abstract: The Principle of autonomy and independence of cooperatives was recovered and analyzed in 1995, when the analysts and scholars of the International Cooperative Alliance decided to review the Cooperative Principles again, which resulted in the incorporation of that principle in the list circulat- 
ing until that time. Each country has a different way of assuming the concepts of autonomy and independence of cooperative entities, in Costa Rica there are multiple manifestations of public entities that analyze their practical application and as cooperatives have seen business opportunities, they have left part of their defense for the autonomy of its decisions, in order to fulfill the social objective defined as the achievement of the economic and social well-being of its associates and the community in which they develop.

Keywords: cooperatives; autonomy; independence; public and private partnerships. 


\section{Antecedentes del principio de autonomía e independencia de las cooperativas, en el cooperativismo mundial y en Costa Rica}

El nacimiento del Principio de autonomía e independencia de las cooperativas lo marcó la Alianza Cooperativa Internacional (ACI), en Manchester, Inglaterra en 1995, hecho acerca de lo cual hay consenso entre la mayoría de los autores, por ejemplo Eguía y MacPherson (1997, p. 175) así como la revisión y precisión de los conceptos que deben ser los contenidos de los Principios Cooperativos realizada por la ACl, en el 2015 (p. 49), a través de sus Notas de orientación para los principios cooperativo. A partir de la consideración del texto del cuarto principio, a saber:

\section{4. ${ }^{\circ}$ Principio: autonomía e independencia}

Las cooperativas son organizaciones autónomas y de autoayuda controladas por sus miembros. Si llegan a acuerdos con otras organizaciones -incluidos los gobiernos - o si reciben capital de fuentes externas, lo hacen en condiciones que garanticen el control democrático por parte de sus miembros y que respeten su autonomía cooperativa.

La $\mathrm{ACl}$ explica que se centra fundamentalmente en la relación de las cooperativas con los gobiernos nacionales y las organizaciones gubernamentales internacionales, aunque también tiene implicaciones respecto a la relación entre cooperativas y otras entidades comerciales, como puede ser un prestamista comercial que aporta capital a una cooperativa, o proveedores y demás agentes en una posición dominante dentro de la cadena de valor.

La unión realizada por Ake (1992, p. 211) y resaltada por Gómez y Martínez (1999, p. 39) de los Principios y Valores cooperativos, es resaltada por la $\mathrm{ACl}$, en sus Notas cuando apunta que:

La integridad de una cooperativa como organización autónoma e independiente radica en los valores cooperativos de autoayuda, responsabilidad propia y democracia, que han sido esenciales en la identidad cooperativa desde la aparición de las empresas cooperativas sostenibles en el siglo XIX.

Para Ake (1992, p. 211) el papel de los Principios Cooperativos siempre ha de servir de guías universales para transformar la esencia cooperativa en práctica, en sus palabras:

Pueden considerarse como el puente entre los ideales y la realidad cooperativa. Sin embargo, como se dijo son sólo medios de 
apoyo. La formulación de los Principios nunca podrá substituir el compromiso con la esencia del modelo cooperativo - y la comprensión del mismo-.

Indudablemente que el reto de la existencia de las cooperativas es cómo sobrevivir dentro de una sociedad capitalista, un mercado cada vez más agresivo y en muchas ocasiones interesado en aprovechar características propias del Cooperativismo, que han sido ventajas competitivas para las cooperativas y por su éxito son adoptadas por las empresas con fines de lucro. Sobre el principio de Autonomía e independencia, en Costa Rica, el legislador en 1968, con la promulgación de la Ley de Asociaciones Cooperativas, incluyó en la legislación especial una protección a las cooperativas frente a las entidades públicas o privadas interesadas en imponer restricciones directas o indirectas a su actividad salvo cuando las disposiciones legales expresamente establezcan esas restricciones. El texto se mantiene:

ARTÍCULO $4 .^{\circ}$ Queda absolutamente prohibido a toda asociación cooperativa realizar cualquier actividad que no se concrete al fomento de los intereses económicos, sociales y culturales de sus asociados. Las cooperativas debidamente registradas gozarán en forma irrestricta de todos los derechos y garantías necesarias para el cumplimiento de sus fines. En consecuencia, serán absolutamente nulos los actos de las entidades privadas o de los órganos públicos que impongan restricciones directas o indirectas a la actividad de esas, asociaciones, salvo cuando las disposiciones legales expresamente establezcan esas restricciones.

Por tanto, las cooperativas quedan absolutamente libres de cualquier tipo de regulación o control por parte de organismos o instituciones del Estado, autónomas o semiautónomas, que la ley no establezca en forma específica.

La formulación de ese principio encuentra su complemento en el inciso K) del artículo 3 de la misma ley, que establece como principio la autonomía en el gobierno y administración de las cooperativas, siempre y cuando las decisiones se ajusten a la ley, se transcribe:

Artículo $3 .^{\circ}$. Todas las cooperativas del país deberán ajustarse estrictamente a los siguientes principios y normas:

k) Autonomía en su gobierno y administración con excepción de las limitaciones que establece la presente ley.

Como han indicado los autores citados, de la aplicación práctica de los Principios y Valores Cooperativos, depende la conservación de las 
cooperativas y su desarrollo en beneficio de los intereses de sus asociados. En Costa Rica los entes públicos relacionados con el Cooperativismo, han contribuido a enmarcar y definir una gama importante de actividades cooperativas, que han incursionado en servicios públicos o han desarrollado actividades económicas controladas por leyes especiales.

Los entes públicos relacionados con las cooperativas, cumplen diversas funciones que les permiten nacer a la vida jurídica y permanecer en el mercado con una guía clara del alcance de sus acciones y los límites de ley. Así el Ministerio de Trabajo y Seguridad Social, encargado de su control y supervisión al principio de la existencia de las cooperativas, tiene como función la inscripción de los actos vitales de los entes cooperativos, en el aspecto registral: constitución, modificación de estatutos, nombramiento de gerente, de miembros de órganos sociales, extinción de la cooperativa. El Instituto Nacional de Fomento Cooperativo encargado de proveer de recursos financieros, de guiar a las cooperativas y controlar así como supervisar su actividad. Y la intervención de la Procuraduría General de la República en la precisión de conceptos y contenidos de leyes que contemplan la relación de las cooperativas con algunos sectores de la economía costarricense, en los cuales han incursionado las cooperativas en aras de su desarrollo.

\section{Valor, respeto y modificaciones a la ejecución de los derechos y deberes derivados del principio de autonomía e independencia, en la perspectiva de algunos y algunas cooperativistas, a través de entrevistas. Perfiles de los entrevistados y entrevistadas}

Aparte de las opiniones emitidas por el INFOCOOP y la Procuraduría General de la República, en relación con el Principio en estudio, y que se incorporan en los diferentes ítems de este ensayo, hay poco análisis acerca de sus alcances y límites. A partir de esa consideración, se analizó la pertinencia de introducir algunas opiniones de cooperativistas sobresalientes en el país, de los cuales no se introduce su nombre pero si se describe sus perfiles.

Se eligieron informantes que laboran en el campo de la docencia en Cooperativismo y que a la vez tienen puestos de dirección en entes cooperativos, sea como directores o asesores legales, asesores en tema de Cooperativismo y Género y con una trayectoria en el Cooperativismo costarricense de más de veinticinco años. A cinco de ellos se les aplicó la entrevista en forma personal y a uno se le envió para que res- 
pondiera mediante grabación de sus opiniones. Todo el material consta en el archivo de esta investigación.

Otro aspecto interesante que se debe apuntar es que los y las informantes no siguieron al pie de la letra el orden de las preguntas de la entrevista formulada, la cual se les entregó en el momento de aplicarla y se les explicó el fin perseguido. Dado la falta de seguimiento de las preguntas, algunas de esas no fueron respondidas puntualmente.

1. El principio de autonomía como una barrera frente a la intervención externa: estatal o de un ente externo relacionado con la actividad económica de las cooperativas.

Esta fue una de las preguntas contestada por todos y el punto de partida fue la existencia de la ley como limite a la actividad cooperativa, ese límite inicia desde el momento en que se impulsa la constitución de una cooperativa. Así, el informante uno apuntó hacia la supervisión y los controles ejercidos por diferentes oficinas estatales:

Uno podría considerar eso. La realidad es que las cooperativas siempre han tenido supervisión y se tienen que ajustar a la normativa, si quiero personería tengo que adaptarme a lo que exige para eso el ente estatal. Para mí, la verdad, no existe la independencia de cooperativas, pues si no cumplo con los requisitos del INFOCOOP no me dan los préstamos. Si no se cumple con Ministerio de Trabajo y no le lleva los documentos que piden, si no les parece no inscribe y aparecen requisitos de pronto.

La informante dos apuntó hacia mayor posibilidad de alianzas y sostuvo que la autonomía de las cooperativas se ve dañada desde que inicia la vida de la cooperativa. Aunque el informante cuatro consideró que lo existente es una reserva de ley. Dice la primera:

Las cooperativas deberían tener mayores alianzas. Desde el momento de su constitución, dañan a la autonomía, al llegar al INFOCOOP un grupo pierde autonomía, le dicen si pueden o no hacerlo, sin estudios técnicos, sino arbitrariamente, serie de lineamientos, reglamentos, si se fuera a un recurso de amparo se ganaría. Si no existe una supervisión diferenciada, se seguirá atentando contra la autonomía de las cooperativas de ahorro y crédito, estas están muy sujetas a esas leyes. Si vamos a hablar de autonomía deberían existir condiciones para aplicarla, intervención de entes estatales e internacionales.

La informante cuatro hace referencia al límite establecido en el respeto a la ley, si bien acentúa el incumplimiento de leyes por parte de 
algunos cooperativistas, en tema de Género. Llama la atención del espacio donde se ubica esa autonomía, que es las necesidades de la gente:

Cuando una persona está en un espacio, tiene que hacer caso a las leyes... Si CR ha firmado acuerdos como CEDAW, BELEM, tiene que cumplir con esos acuerdos, algunos cooperativistas dicen que no tienen que cumplir porque son entes privados.

... se debería ver como se manifiesta a través de una asamblea, en términos de control democrático. Tienen que preguntarle a la gente que quieren, les preguntan a las mujeres qué quieren. La AUTONOMÍA debe manifestar desde lo que quiere cada grupo. En este momento, hay un síntoma que se llama la gerentitis, el gerente hace lo que quiere.

El informante cinco apuntó a los orígenes del Principio en la LAC así como el respeto que se ha tenido de su existencia por parte de entidades públicas, y más bien han sido las cooperativas la que han permitido la injerencia en sus estructuras:

En C.R. tenemos la ventaja que el principio se plasmó desde los orígenes en la LAC, hace unos 50 años, por lo cual nunca se ha dado que una entidad pública imponga cargas a las cooperativas. Si conozco casos donde las cooperativas por disposiciones meramente contractuales o crediticias si han permitido el acceso de entidades financieras sobre todo en sus cuerpos directivos como un punto de control. Lo he podido observar en las Participaciones Asociativas donde se le ha inyectado dinero a algunas cooperativas.

El informante seis trae a colación la contratación entre las cooperativas y entes públicos para desarrollar actividades de interés público, en forma concreta la dotación de salud. Lo ve como una forma de restricción de la autonomía, en tanto que las decisiones del representante se sobreponen al ejercicio democrático de los derechos de los asociados dentro de la cooperativa:

Entonces esa autonomía de la gestión muchas veces se ve comprometida por el contrato de servicios que algunas cooperativas tienen como las electrificación y salud y a la hora de adherirse al contrato esa autonomía que en principio existe, lo que es cierto no opera como tal. Un ejemplo. Dentro del decisión operativa de una cooperativa de Salud está el nombramiento de un director médico — su nombramiento debe ser aprobado por la Junta de Salud, la máxima autoridad técnica- Es el jefe de todos, de la jefatura de farmacia, de 
medicina, en general. Ley de descentralización de la CCSS que crea las Juntas de Salud. Lo cual es una acto basado en el principio de la autonomía de la voluntad para contratar un funcionario y si es de autogestión, debería ser un asociado que preste ese servicio pero en este caso hay una norma que establece que la Junta de salud, que es la representante de la comunidad tiene injerencia en ese nombramiento.

2. ¿Sería o es sana la intervención de terceros como socios capitalistas, ¿cuándo se requieren recursos económicos para impulsar el desarrollo de la cooperativa? Por ejemplo: bancos estatales o privados, pensionados o interesados únicamente en mantener depósitos a plazo para obtener mayores ganancias en los intereses generados.

Las respuestas fueron dirigidas a considerar que las cooperativas únicamente deben servir a sus asociados. De cuatro respuestas tres fueron en esa vía, mientras que la última consideró importante esa apertura, bajo la condición de una actividad debidamente regulada.

El informante uno:

No estoy de acuerdo con los socios capitalistas, distorsiona totalmente el modelo, no es un tema ni de ganancia o intereses ganados, lo que interesa en la Cooperativa es el acto cooperativo y se justificaría el cobro de renta.

El informante dos:

Te diría al igual que lo anterior, la autonomía debe estar frente a la naturaleza inherente de las cooperativas, no se puede pensar solo en las ganancias, cualquier actividad de la cooperativa, las cooperativas son entidades sin fines de lucro. No es que las cooperativas no puedan interactuar con otras empresas económicas, sin perder la independencia, pero sin desnaturalizar a la cooperativa.

El informante tres:

Coopenae, personas invierten sus recursos, socios capitalistas, no son asociados, intermediación financiera cooperativa, debe ser con los propios asociados.

Respecto de los contratos de Participación asociativa manifestó:

A los años son los problemas, después de recibir el dinero, les empiezan a molestar las cláusulas de la PARTICIPACIÓN ASOCIATIVA. COCAFE. 
Mientras que el informante cinco considero oportuna esa participación y como se indicó siempre que se trate de una actividad financiera, lícita y regulada:

Este tema de que las cooperativas acudan a la participación de bancos privados o personas solo tengan interés de realizan depósitos a plazo, yo lo dejaría a que se trate de una actividad financiera licita regulada y técnicamente recomendada y no veo que las cooperativas no puedan realizar esa actividad, en el tanto se encuentren reguladas por la normativa de intermediación financiera y que de ninguna manera no pongan en riesgo el patrimonio de los asociados y regulen internamente hasta donde llegaría la participación de esos inversionistas teniendo como norte que con base en el principio de autonomía no podría verse afectada la toma de decisiones por los órganos sociales de la cooperativa.

3. Sobre los alcances y límites de la autonomía e independencia de las cooperativas hay diversidad de criterios y opuestos, para un informante no están claros, para otro si lo están en la ley, otro los califica de difusos, y en el caso de contratos con entes públicos no los hay, Únicamente un informante considera que existen límites a la posible violación de la autonomía de las cooperativas, lo cual se encuentra claramente establecido en la ley y con apoyo reiterado en la jurisprudencia, cuando se trata de los derechos de los asociados y su ejercicio en las asambleas.

El informante uno:

Igual, es tema difícil que lo veo muy difícil de poder delimitar, se podría decir que la cooperativa es libre para administrarse. No lo es con los otros, una cooperativa es libre para hacer su asamblea, pero que hay control del Ministerio que considera que hay acuerdos no son válidos y debe hacerse otra asamblea. Para mí los límites no están claros.

El informante tres:

El artículo 4 establece que a nivel de ley son los límites. Si la asamblea lo aprueba, si se pretende por parte de un tercero imponer sus cláusulas.

El informante seis:

Es posible, es autónoma en su gestión interna, pero tiene límites muy difusos dependiendo en el giro del negocio del que se en- 
cuentre, si el giro económico es la prestación de un servicio público a cargo del Estado se puede decir que no hay.

El informante cinco:

Si como lo mencioné hace 5 décadas, básicamente lo que establece esta norma es que las cooperativas no pueden... No puede haber injerencia en las cooperativas, esa norma muy bien pensada por los legisladores de que se tratan organizaciones de derecho privado.

Hay jurisprudencia en el sentido de que la asamblea es solo de los asociados y se han basado en el principio de autonomía y no deben participar terceros aunque sean colegas con base en el principio de autonomía.

4. Límites establecidos en la gobernanza impuesta por los entes financieros: internos y externos a Costa Rica un límite a las cooperativas de intermediación financiera. Hubo tres percepciones diferentes acerca de lo planteado: el primer informante si lo ve como intromisión y tratar a la cooperativa de intermediación financiera como un ente financiero internacional. El segundo consideró que no afecta en su autonomía y que deben seguir ciertas pautas internacionales para no quedar fuera del negocio. Mientras el tercero considera que no roza con la autonomía, pues si a la cooperativa le interesa participar en algún negocio con otras reglas tiene que someterse.

El informante uno:

Me deja gran duda. La introducción de un tercero en cooperativas de Intermediación financiera dentro de su Consejo de Administración, si es una intromisión, es un acto contra todo principio de autonomía e independencia de la cooperativa. Yo puedo exigir, más bien recomendar, que la gente que esté ahí esté preparada, que conozca el negocio de la cooperativa, pero meterle externos, obligarla, va contra ese principio. Incluso quieren comparar a la cooperativa con un ente financiero internacional, pero la cooperativa no tiene las mismas prerrogativas de las otras. Hay intromisión de la gobernanza de las cooperativas.

El informante tres:

La normativa contable internacional, es de aplicación para toda organización, si bien no es exigible se aplique, la recomendación del Colegio de contadores es que las cooperativas se vayan adhiriendo a este tipo de normativa. El INFOCOP es respetuoso y comparte ese criterio. Considera que no es un golpe a la autonomía, sino que toda 
empresa debe adaptarse, por ejemplo si no lo hace NIFFS, ningún despacho de auditores va a querer hacer la auditoría.

\section{El informante cinco:}

Creo que en esto debemos tener presente lo siguiente. Cuando una cooperativa ingresa en cierto tipo de actividades luz, intermediación, etc. tiene que ajustarse a... Si un grupo han escogido ser cooperativa ahorro y crédito tienen que ajustarse a la normativa de ese sector. Eso no violenta el principio de autonomía porque cuando una cooperativa decide ingresar a algún sector, tiene que ajustarse a la normativa. Y eso funciona para todas las cooperativas como servicios públicos como transporte salud, electricidad, existen regulaciones a las que deben someter, no violenta la autonomía.

Y no roza con el principio de autonomía que dice que no se pueden establecer limitaciones que no estén en la ley y recordemos que todo eso está' delimitada en el ordenamiento jurídico.

5. Las cooperativas no dependen de nadie, como sociedad o empresa, sino que se gobiernan por sus propios socios. Posibilidad de contradicción con la actividad de control y supervisión ejercida por el INFOCOOP, o de otros entes que les imponen cargas para desarrollar su giro económico. Al respecto, hay cierto consenso en cuanto a la autonomía de los asociados para tomar sus decisiones al interno, pero como las cooperativas están inmersas en la realidad del país, tienen que acatar sus regulaciones para lograr su desarrollo.

El informante uno:

Tampoco es cierto, en cualquier mercado o servicio, una cooperativa de transporte debe ajustarse a las directrices de transporte público. Vivienda, no es cierto que no dependen de nadie sino que están sujetas la legislación específica. Dependen de la legislación del todo el país.

El informante tres:

En buena teoría así debería ser, que es su propia asamblea la que toma las decisiones, sin embargo, no hay que perder de vista que las cooperativas viven inmersas en toda una realidad económica.

El informante cinco:

Retomo lo dicho en el punto anterior, la gestión democrática de sus propios asociados, pero deben ajustarse a la supervisión de 
su sector, entonces en su giro económico la cooperativa debe ajustarse a lo indicado por la ley, llámese supervisión financiera, del INFOCOOP, como toda empresa debe respetar las regulaciones legales atinentes.

6. Conocimiento de los antecedentes de la introducción de este principio cooperativo.

El informante uno:

Porque es lo lógico y razonable, ojalá las cooperativas pudieran tener autonomía e independencia y el propio movimiento, pero no se puede soñar con una independencia absoluta, sería un paraíso fiscal para ponerlo en esos términos y no es real. Sería ideal pero no es posible.

El informante tres:

No conoce los antecedentes.

El informante cinco:

Sobre el principio cooperativo de autonomía me parece ha sido uno de los grandes aportes de la ACl, de ir perfilando los valores los principios a que deben ajustarse las cooperativas para mantener su esencia. Ha hecho bien de irlos delimitando para evitar que se desnaturalicen y han permeado en los legisladores y muchos ellos incluidos en la legislación costarricense.

7. Se solicitó una valoración del Principio de Autonomía, en Costa Rica, considerando las acciones de diputados y otros miembros del Gobierno actual que han pretendido gravar los excedentes de las cooperativas. La respuesta en general ha sido que no ha estado presente en las discusiones. Más bien, el tema de imposición tributaria ha tomado el camino de gravar los excedentes.

El informante uno:

No ha contribuido, es que el principio que menos ha contribuido al modelo cooperativo. Cuando se va a ver el tema de cargas, no se discute en ningún momento. No se ha tocado.

El informante cuatro:

Las cooperativas deben demandar al Estado lo que los asociados quieren.

Boletín de la Asociación Internacional de Derecho Cooperativo

ISSN: 1134-993X • ISSN-e: 2386-4893, No. 55/2019, Bilbao, págs. 55-86

doi: http://dx.doi.org/10.18543/baidc-55-2019pp55-86 • http://www.baidc.deusto.es 
El informante cinco:

Creo que el tema tributario de las cooperativas, la discusión no ha venido por el principio de autonomía, sino por la forma particular en que las cooperativas operan, las cargas parafiscales que se han impuesto en CR., que son diferentes a una sociedad mercantil, la forma en que contribuyen los asociados en los excedentes que puede ser una doble imposición, si se cobra al asociado y a la cooperativas en forma separada, me parece que más bien la discusión se ha ido más por esos ámbitos y no con base en el principio de autonomía.

8. Se solicitó una opinión adicional sobre el tema en discusión, el informante cinco manifestó:

Básicamente, yo creo que este principio le sirve de escudo a las cooperativas para que toda injerencia de terceros en su actividad empresarial... deba pasar por el tamiz de la discusión legislativa para establecer por una ley expresa la regulación de que se trate...

De los insumos obtenidos en las entrevistas sobresalen los siguientes aspectos:

- No hay conciencia en el Cooperativismo nacional sobre los alcances del Principio de Autonomía, por lo cual no ha sido aprovechado en la defensa de los derechos de las cooperativas y sus miembros.

- Las cooperativas que tienen interés en participar en el desarrollo de servicios públicos como la salud, transporte, o bien, actividades muy reguladas por el Estado como comercialización internacional del café o intermediación financiera, entre otros, no pueden escapar a seguir la normativa general que se dicta para todo el sector.

— Falta un mayor análisis y discusión de los Principios cooperativos, su valor y su relación con los valores, pues el principio de autonomía no ha sido asimilado más allá de los casos concretos, que serán estudiados en los siguientes apartes de esta contribución.

\section{Límites a la autonomía e independencia de las cooperativas según giro comercial o incursión de las cooperativas en la ejecución de algunos servicios públicos}

En seguimiento al análisis introducido mediante la recepción de opiniones de algun@s connotad@s cooperativistas, se tomarán en cuenta algunos ejemplos relacionados con la modificación del Princi- 
pio de autonomía cooperativa, ya sea a través de convenios que están regulados en leyes o reglamentos, mediante los cuales se permite a los entes cooperativos incursionar en actividades regladas o consideradas de interés público como son los servicios de electricidad y salud, entre otras.

\subsection{Cooperativas de caña de azúcar y obligación de compra a un productor no asociado}

En 1997 surgió la duda sobre la obligación de las cooperativas de producción de azúcar, en relación con productores no socios. Se discutió si un ingenio organizado como cooperativa estaba obligado a comprar caña de un productor no asociado a efectos de industrializarla. La posición del INFOCOOP, que el productor debería asociarse previamente a la Cooperativa para gozar de sus servicios, porque en su criterio, la cooperativa sólo puede prestar sus servicios a asociados, en vista de la prohibición del artículo 9 de la LAC que somete a las cooperativas a obtener una autorización por parte del Instituto, cuando tengan interés en extender sus servicios a personas no asociadas.

Según la Procuraduría General de la República (PGR) el principio es que las cooperativas funcionan en relación con sus asociados. De modo que si se trata de una cooperativa de servicios, éstos solo se prestan a los asociados. En principio, es potestativo de cada cooperativa decidir, si sujeta a la aprobación del INFOCOOP la extensión o no esos servicios. Empero, esta disposición no puede ser interpretada aisladamente, sin considerar el resto del ordenamiento jurídico, que puede tanto restringir el derecho de contratar con terceras personas, como permitir prestar el servicio a terceros. La actividad cooperativa, como toda actividad, está sujeta a la regulación legal. Aspecto que no escapó al legislador ni a los fundadores del movimiento cooperativista. Dictamen C-054-97, de 9 de abril de 1997.

La PGR se fundamenta en la letra del artículo $4 .^{\circ}$ de la Ley de Asociaciones Cooperativas, donde encuentra el fundamento de la garantía de la autonomía del movimiento cooperativo. La PGR considera que no es absoluta y que, conforme con el Estado de Derecho, no se ejerce frente al legislador. De modo que la ley puede imponer restricciones, directas o indirectas, a la actividad de las cooperativas, así como sujetar esos entes al control o regulaciones de otras entidades. Lo que reafirma que la autonomía se ejerce dentro de la ley. Significa lo anterior que en el tanto en que la Ley no restrinja directa o indirectamente dicha autonomía, la cooperativa decide libremente su actuación, lo que 
conlleva la imposibilidad jurídica de que terceras personas, públicas o privadas, la restrinjan en su accionar o la controlen, salvo - repetimos - disposición en contrario de la ley. Pero si la ley entra a regular la esfera de acción de la cooperativa, o bien la actividad a que ésta se dedica, la cooperativa no es libre de actuar en forma diferente.

Pero, basada la Procuraduría en la existencia de una ley especial, que es la Ley de la Agricultura e Industria de la Caña de Azúcar, N. 3579 de 4 de noviembre de 1965 —os artículos 18 y 42, inciso f) — dispone que los ingenios organizados como cooperativas están obligados a recibir caña de productores independientes no socios de la cooperativa, el criterio tiene que variar cuando se trata de órdenes de compra y procesamiento de la caña de azúcar. De tal modo, que en virtud de la libertad de asociación, por una parte, y del respeto debido a la ley, por otra parte, la cooperativa dueña del ingenio no podría condicionar el recibo de ese producto a la afiliación previa del productor independiente.

2.2. Participación de personas jurídicas como asociadas de cooperativas. Límites a la autonomía: incursión en otro tipo de negocios, compra de sociedad mercantil

En principio, la LAC permite la afiliación de personas jurídicas a las cooperativas, bajo condición de que no persigan fines de lucro, cuya letra es la siguiente:

Artículo 56. Para ser miembro de una cooperativa se requiere poseer los requisitos o condiciones exigidos por los estatutos.

Podrán ser miembros también las personas jurídicas que no persigan fines de lucro, aunque no reúna todos los requisitos que indiquen los estatutos. Se exceptúan las cooperativas de autogestión, en las cuales las personas jurídicas no podrán ser miembros.

El INFOCOOP ha sido firme en su posición de rechazar la incorporación de sociedades anónimas a las cooperativas, en condición de socias, por la oposición en sus fines sociales, dado que las sociedades mercantiles se crean y funcionan con base en la obtención de lucro -tesis sostenida en sus dictámenes MGS-443-2004 del 6 de julio de 2004 y MGS-976-691-20 10 de 1 de octubre del 2010-.

Sin embargo, la ley cooperativa, en forma excepcional permite la asociación de personas jurídicas con las cooperativas, siempre y cuando sean cooperativas de servicios, con la finalidad de suplir necesidades en el campo de la agricultura, la ganadería y la industria y no usen los ser- 
vicios de la cooperativa con fines de lucro y previa autorización del INFOCOOP -12 inc. b) - Y Y en la legislación cooperativa costarricense, las cooperativas de autogestión están excluidas de cualquier asociación externa, porque es imposible por la misma naturaleza de la membresía y forma de trabajo, como se puede leer del artículo 56 antes transcrito.

Mientras en las cooperativas de cogestión, desde su misma constitución, productores o el Estado en alguna de sus manifestaciones, pueden formar parte de ese tipo de cooperativas, con base en la reforma introducida en 1982, año en que fueron creados dos nuevos modelos cooperativos, basados en la forma de acceso a la propiedad y su control. En relación con las cooperativas cogestionarias, el artículo 121 las describe y el 122 indica la forma de participación y la distribución de derechos y cargas:

Artículo 121. Las cooperativas de cogestión tienen por objetivo la producción y transformación de bienes o la prestación de servicios con la participación directa de los trabajadores y los productores de materia prima, del Estado y los trabajadores o de los trabajadores, los productores de materia prima y el Estado (primer párrafo).

Artículo 122. En las cooperativas de cogestión entre el Estado y los trabajadores, el porcentaje de los excedentes que corresponde a los trabajadores se fijará tomando en cuenta: la rentabilidad de la empresa, el valor agregado por el factor trabajo y las inversiones efectuadas por el Estado y por los trabajadores. En el caso de empresas ya existentes en manos del Estado cuyos excedentes estén financiando otras actividades de éste y que se transformen en cooperativas de cogestión Estado-trabajadores, deberá tomarse en cuenta además las necesidades que el Estado estuviera cubriendo con el producto de la operación de la empresa. El porcentaje de los excedentes que corresponda a los trabajadores deberá distribuirse entre todos los trabajadores, incluidos los trabajadores temporales cuya parte correspondiente del porcentaje de dicho excedente, se calculará con base en el trabajo aportado.

\subsection{Electrificación como servicio público prestado por cooperativas de electrificación rural y su posibilidad de emitir títulos valores para ser captados por terceros}

En Costa Rica existen cuatro Cooperativas de Electrificación Rural: COOPEGUANACASTE R.L. (Cooperativa de Electrificación Rural de Guanacaste), fue fundada el 10 de enero de 1965. COOPELESCA R.L. (Cooperativa de Electrificación Rural de San Carlos) fue fundada el 24 de enero de 1965. COOPESANTOS R.L. (Cooperativa de Electrificación 
Rural de los Santos) fundada el 17 de enero de 1965. COOPEALFARORUIZ R.L. (Cooperativa de Electrificación Rural de Alfaro Ruiz) fundada en 1972); cuyos objetivos son:

- La representación y defensa conjunta.

- La producción de energía.

- Adquisición de bienes y servicios en forma conjunta.

- Transferencia de tecnología.

Lo esencial de su historia y el servicio que prestan consiste en la situación del servicio de energía eléctrica antes de su constitución, pues las áreas servidas por estas poseían una electrificación muy escasa, se limitaba a las zonas urbanas importantes (algunas cabeceras de cantón) y en algunos distritos a la pulpería, cantina y algunas casas, generalmente pertenecientes a familiares cercanos o al mismo dueño de esos comercios, quien era dueño a su vez del generador eléctrico, usualmente movido por un motor de combustión interna; la electrificación rural como tal no existía.

A partir de la emisión de la Ley que Autoriza la Generación Eléctrica Autónoma o Paralela, Ley N. 7200 de 28 de septiembre de 1990, se permite a las cooperativas integradas al Sistema eléctrico nacional la generación autónoma o paralela de energía eléctrica —artículo 1-. Esa Ley autoriza la generación para venta de electricidad al ICE, a partir de centrales eléctricas de capacidad limitada para explotar el potencial hidráulico en pequeña escala y las fuentes de energía no convencionales, y se ha declarado de interés público —artículo 3-.

La mencionada generación eléctrica se fortalece con la emisión de la Ley de Participación de las Cooperativas de Electrificación Rural y de las Empresas de Servicios Públicos Municipales en el Desarrollo Nacional, Ley N. 8345-2003. Así, en dictamen de la PGR N. C-062-2010 de 12 de abril de 2010, en su análisis, indicó que los sujetos privados se encuentran imposibilitados para producir energía eléctrica para fines distintos al propio consumo. Una generación para venta a terceros sólo puede realizarse en el marco de la Ley N. 7200 o bien, en tratándose de asociaciones cooperativas de electrificación rural, a consorcios formados por estas, en los supuestos de la Ley N. ${ }^{\circ} 8345-2003$, que no se aplica al ICE. Y como estamos en el ámbito de acción del ICE, fuera de los supuestos de la Ley N 7200 que debe ser analizada en relación con la N. 7593, no es posible la generación para la venta de energía a un usuario, aun cuando éste sea el ICE. Por el contrario, como indica la ARESEP, la estructura del mercado eléctrico costarricense supone la figura de un comprador único (el ICE) que le compra energía a los generadores privados, mediante concesiones, contratos y tarifas establecidos o aprobados. 
Ante los problemas suscitados por la ausencia de un marco regulatorio para autorizar el otorgamiento de las fuerzas de las aguas de dominio público para generación eléctrica, el legislador emitió la Ley N. 8345 para permitir a las empresas municipales y las cooperativas de electrificación rural contar con la concesión de agua necesaria para la generación de energía eléctrica. La Ley define la cooperativa de electrificación rural como una Asociación cooperativa creada para solucionar primordialmente el problema común de la falta de energía eléctrica en las áreas rurales, así como su distribución y comercialización -artículo 2, inciso d) - . En ese artículo también se reconoce la existencia y autorización de funcionamiento del consorcio constituido por estas (Coneléctricas R. L) y en su conjunto forman parte del Sistema Eléctrico Nacional y del Sistema Eléctrico Nacional interconectado.

La integración de esas cooperativas al Sistema Eléctrico Nacional les obliga a seguir las disposiciones y condiciones de funcionamiento, según lo establece el artículo 5 de la Ley, los reglamentos emitidos por el ICE, respecto de la operación integrada del Sistema, todo con el objeto de garantizar la seguridad y calidad de la energía y por ende, del servicio público de generación, transmisión y distribución de ésta. Entre los aspectos más relevantes se pueden mencionar:

- Las cooperativas de electrificación rural están obligadas a prestar el servicio en el área de la concesión: su ámbito de acción viene determinado por la concesión y no por la afiliación o asociación.

- Cada cooperativa debe prestar sus servicios a todos los usuarios, independientemente de que estos sean o no asociados y lo que es más importante a proveer el servicio en condiciones de igualdad —artículo 6- su concesión y conforme al artículo 13 de la Ley N. ${ }^{\circ}$ 7593, de 9 de agosto de 1996.

Como parte de las actividades que pueden realizar las cooperativas de ese tipo, para financiarse, se encuentra la posibilidad de realizar oferta pública de valores, para captar de sus asociados o terceros, lo cual está incluido dentro de su marco legal específico que las habilita para obtener recursos de esa forma para el cumplimiento de sus fines. Sin embargo, en algún momento el Superintendente de Valores, dudó de esa autorización y por ello solicito a la PGR la aclaración del dictamen N. C-291-2011, y de ahí surgió el dictamen C-019-2013 de 13 de febrero, 2013.2

2 http://www.pgrweb.go.cr/scij/Busqueda/Normativa/pronunciamiento/pro_ficha. aspx? param1 =PRD\&param6=1\&nDictamen=17493\&strTipM=T 
Para las cooperativas de electrificación rural la Ley no establece una autorización expresa para participar en el mercado financiero primario o secundario, particularmente para emitir valores y hacer oferta pública de valores, como sí lo dispone el artículo 15 para el ICE y sus empresas. Empero, implícitamente se autoriza esa participación, ya que se dispone que las operadoras de pensiones, sociedades de mercado de capitales y sociedades administradoras de fondos de inversión para que inviertan en valores emitidos por las entidades del servicio eléctrico, entre ellas las cooperativas de electrificación rural —artículo 19-.

\subsection{Participación entes públicos: convenios de gestión de servicios de salud de la C.C.S.S. y cooperativas}

En el cooperativismo costarricense existen varios ejemplos de participación de algunos entes públicos dentro en su actividad, basados en busca de su fomento. Entre los entes públicos que se pueden asociar se encuentran las municipalidades, limitadas a su jurisdicción territorial —artículo 14 LAC—; el INFOCOOP autorizado por ley para participar, cuando esa asociación justifique el impacto nacional o regional del proyecto correspondiente. Por supuesto, deberá existir un estudio previo que acredite mediante un estudio de factibilidad la importancia del mismo - (artículo 157) - . O bien, al externo del cooperativismo nacional, se cuentan alianzas con entes públicos que promueven el bienestar de la población en el campo de la salud, de servicios eléctricos, entre otros el establecimiento y desarrollo de cooperativas, y entre las formas de auxiliarlas permite la conversión de aquellas como asociadas, con base en leyes especiales que lo autorizan.

En el campo de la salud de la población, una institución autónoma como es la Caja Costarricense de Seguro Social (CCSS) inició en 1988, una experiencia de contratación de servicios de salud con COOPESALUD R.L., mediante un convenio para impulsar un «Nuevo Modelo de Atención en Salud» centrado en la atención integral y continua, orientada a la familia, a la comunidad y a la administración de los servicios de salud, en el distrito sede de la cooperativa. El 6 de febrero de 1989 el Ministerio de Salud le traspasó sus programas, constituyéndose así, en un Sistema Local de Salud totalmente integrado, hecho que se convirtió en uno de los cambios más importantes de la Seguridad Social Costarricense, durante la década de los ochenta, ya que por primera vez en el país, una empresa privada asumía la prestación de servicios que hasta ese entonces eran brindados únicamente por la Caja y el Ministerio de Salud. 
Por los resultados favorables en la experiencia de Coopesalud R.L., en 1989, nacieron otras cooperativas de salud con objetivos similares a la primera, así en 1990 la Cooperativa Autogestionaria de Salud Integral, COOPESAIN R. L, en 1993 la Cooperativa Cogestionaria de Salud de Santa Ana, COOPESANA R.L., y la Cooperativa Autogestionaria de Medicina Integral, MEDICOOP R.L.

Varios años transcurrieron, hasta lograr en 1997, la emisión de un pronunciamiento de la Contraloría General de la República, que estableció la facultad de contratación de la CCSS para contratar la prestación de servicios a empresas privadas, dejando claro que «...siempre y cuando con esa operación se proponga disminuir los costos administrativos que emplea en la prestación directa del servicio, o bien, se proponga hacer un mejoramiento puntual y progresivo de la atención que se preste al usuario...», Dentro del contrato se establece que cada Cooperativa tiene la carga de asumir el costo de los equipos, los inventarios, el mobiliario, el mantenimiento, las ampliaciones y modificaciones de infraestructura, aunque en los primeros años fueron asumidos por la CCSS. ${ }^{1}$ Luego, según informa La Nación digital, los convenios con las cuatro cooperativas de salud que brindan servicios en varias comunidades del país, se han ido prorrogando.

\subsubsection{CONVENIOS SUJETOS A LA ORGANIZACIÓN DE LA CCSS. LAS JUNTAS DE SALUD Y DIRECTOR MÉDICO DEL CENTRO DE SALUD}

La ley N. 7852 de 1998, por medio de su artículo primero impulsa el proceso de desconcentración de los hospitales y las clínicas de la CCSS, con el fin de permitirles mayor autonomía en la gestión presupuestaria, la contratación administrativa y el manejo de los recursos humanos. Esa ley crea las Juntas de Salud como entes auxiliares de la gestión de los centros de salud, con el fin de mejorar la salud integral de la población, el desempeño administrativo y financiero, promoviendo la participación social, en una clara búsqueda de la transparencia, calidad y sana administración de los servicios de salud brindados a los usuarios -artículos 1 y 2 -

De acuerdo con las funciones otorgadas por la ley en mención, a las Juntas de Salud, en cada centro hospitalario o clínica, existe una afectación de la autonomía en el gobierno de la cooperativa, que funciona como clínica, por varias razones, aunque se parte de la suscripción de un contrato de prestación de servicios de salud por medio de clínicas privadas y del marco del Derecho Privado en la actividad cooperativa. Los miembros de las Juntas de Salud son siete y son elegidos en forma popular y 
democrática: tres representantes del sector de los asegurados, dos representantes de los patronos de la zona de atracción del centro de salud y dos de la Asociaciones y Organizaciones Pro-Salud, por lo cual tampoco en esas Juntas de Salud participa directamente la Cooperativa de Salud. A las Juntas de Salud les corresponde, entre otras funciones:

- Colaborar con los directores de los establecimientos de salud, en la elaboración de los anteproyectos y las modificaciones presupuestarias de la Institución.

- Emitir criterio respecto de los candidatos al cargo de Director General del establecimiento de salud. En los establecimientos de salud públicos gestionados por terceros, la Junta de Salud se pronunciará sobre los candidatos a Director, Gerente o cualquier puesto de naturaleza similar.

- Participar en opiniones y recomendaciones, en la definición de prioridades y políticas generales. En los establecimientos de salud públicos gestionados por terceros, la Junta de Salud procurará que las decisiones se ajusten a la conveniencia y necesidades de los usuarios de los servicios de salud.

Cada clínica de cooperativa, según la Ley de desconcentración de hospitales y clínicas de la CCSS, es administrada por un Director, quien debe actuar siempre conforme a los objetivos y las obligaciones señalados en el compromiso de gestión suscrito con la CCSS, los reglamentos generales y lineamientos de política que emita esa Institución —artículo 9-. Además es el representante del centro de salud, con las facultades establecidas en el acuerdo de su nombramiento, realizado por la Junta Directiva de la CCSS y es el responsable de su gestión ante la misma -artículo 10-. Además las juntas de salud de dichos centros, coadyuvarán a la fiscalización y definición de sus prioridades y participarán en la ejecución de éstas.

De tal modo, que derivado de la firma de un convenio de gestión de salud, se traslada a cada cooperativa parte de su control democrático, la autonomía en el gobierno así como su independencia de criterio a terceros como son el Director de la Clínica y la Junta de Salud correspondiente. Aunque mantiene su estructura democrática tanto política como ejecutiva según la LAC, a saber, la participación en las asambleas únicamente de sus miembros, la elección de los órganos sociales a través de las asambleas y el nombramiento de un gerente, por parte del Consejo de Administración —artículos 37 y 56 de LAC - para todos los asuntos económicos y sociales que no dependan del criterio técnico del Director de la Clínica ni de la fiscalización 
y definición de prioridades que realice la Junta de Salud dentro de cada Clínica.

\subsection{Límites del INFOCOOP: deber de abstención en la toma de decisiones de las cooperativas. Posición no vinculante de sus criterios}

Es común, en la vida práctica del Cooperativismo costarricense, acudir al INFOCOOP, a realizar consultas sobre temas diversos de la actividad de los entes cooperativos. Generalmente las realizan los miembros de órganos sociales, el gerente o los asociados de las cooperativas, para obtener su criterio acerca de alguna situación de gobierno propio de las cooperativas, tales como decisiones del Consejo de Administración, contenido de los acuerdos, fijación de días de sesión, tiempo de duración de ésta, solicitud de un aval acerca de una decisión de uno de los órganos sociales, el ejercicio democrático de los derechos por parte de los socios, en las asambleas, por mencionar un número pequeño de casos.

Frente a esas solicitudes, y en respeto del Principio de autonomía de las cooperativas, el INFOCOOP se ha mantenido al margen de intervenir en la vida interna de los entes cooperativos. Este se ha apoyado en el marco establecido por la Procuraduría General de la República, que reconoce la función consultiva del Instituto, pero establece muy claramente que no puede participar en la toma de decisiones de una Cooperativa o sustituir las decisiones que hayan tomado los órganos sociales de la misma.

El rol que debe jugar el INFOCOOP está definido en el artículo 157 inciso n) de LAC, que establece la función consultiva por medio de la emisión de un criterio técnico-jurídico sobre las consultas relacionadas con la normativa o doctrina cooperativa, para colaborar en la toma de decisiones de sus órganos sociales, siempre y cuando ese criterio no esté dirigido a la solución de casos concretos, pues se estaría violando la autonomía de la cooperativa. Esos límites han sido establecidos en varias y reiteradas comunicaciones del INFOCOOP a los entes cooperativos, se deja la cita a modo de ejemplo del criterio MGS-234613-2010, de 11 de marzo del 2010. Sobre consulta sobre decisiones de Consejo de Administración, cursada por el gerente, la respuesta se basó en los artículos 3 inc. k) y 4, con indicación de la falta de competencia del INFOCOP para conocer de ese tipo $Y$ que la facultad otorgada en el artículo 157 inc. k) de LAC. En esa respuesta se acentúa la función única de interpretación de la esa normativa. SC-588-2015. 22 de junio de 2015. También es importante aclarar que los criterios refe- 
ridos en el párrafo anterior, no son vinculantes para las cooperativas. Ver criterio SC-592-2015 de 23 de junio de 2015.

\subsection{Nulidad de asambleas por control de legalidad del Ministerio de Trabajo y Seguridad Social (MTSS)}

En Costa Rica, las asambleas de cooperativas pueden declararse nulas cuando se incumple algún requisito esencial para su convocatoria, o ésta es ausente; también podría ser que los aspectos tratados debieron considerarse en una asamblea extraordinaria. Esa declaratoria ha variado en cuanto a la competencia del ente público, en sede administrativa: el INFOCOOP o el MTSS. Antes de 2006, correspondía al INFOCOOP declarar la nulidad de las asambleas, pero con el Dictamen C-490-2006 de la PGR, se analizó la competencia administrativa del Instituto, de acuerdo con la LAC, y se encontró un vacío respecto de la extensión del control de la legalidad de las cooperativas, pues no se le había atribuido expresamente la potestad de anular los actos cooperativos, de tal modo que la competencia al momento es del Ministerio. Además, dentro de ese dictamen la PGR estableció claramente el respeto debido al Principio de libertad que debe privar en las cooperativas y cuya vía para restringirlo únicamente puede ser a través de una ley o reglamento que la desarrolle, se transcriben algunos conceptos sobresalientes del Dictamen:

El establecimiento de un ente de control de las cooperativas constituye una excepción al principio de autonomía dispuesto en el segundo párrafo del artículo 4 de la Ley.

La autonomía de las cooperativas, entidades privadas, impide que el Estado u otros organismos públicos puedan regularlas o controlarlas en los supuestos no previstos por la ley. Es el principio de libertad que impide el establecimiento de restricciones por norma inferior a la ley, por una parte y el imperativo de que el desarrollo de la cooperativa no sea perturbado por elementos externos a los fines cooperativistas, por otro lado.

La restricción de un derecho fundamental sólo puede tener su origen en una ley o bien, en un reglamento que desarrolle lo dispuesto en una ley. El control público sobre una entidad privada implica una fuerte restricción al principio de libertad que rige al sujeto privado y eventualmente, a la libertad de empresa. Recuérdese que la autonomía privada permite al sujeto privado el poder de «gobierno» de la propia esfera jurídica. Poder que se manifiesta en las relaciones jurídicas en que participa el sujeto privado. Un poder tutelado por una libertad fundamental: la libertad personal. 
En tema de competencia el artículo 33 de la LAC, la reserva al MTSS, en cuanto a la inscripción de cooperativas y de los acuerdos de la asamblea general. La inscripción procede si no existieren impedimentos legales y objeciones. El Ministerio puede inscribir, rechazar o suspender la inscripción de una nueva cooperativa o las modificaciones a estatutos o el nombramiento de nuevos directivos de órganos sociales o del gerente.

\subsection{Participaciones asociativas del INFOCOOP y entes cooperativos}

Desde el 2006 el INFOCOOP, por medio de su Junta Directiva tomó la decisión de apoyar los organismos cooperativos por medio de contratos denominados Participaciones Asociativas, mediante los cuales les traslada recursos económicos. El fundamento legal lo ofrece la LAC, artículos 95 párrafo tercero, 157 inciso h) y 162 inciso c), y el Reglamento de participaciones asociativas dictado en ese año, y modificado en un período de once años, siete veces y para efecto de este ensayo se ha tomado la versión vigente al 9 de junio de 2017, publicada por el Sistema costarricense de información jurídica.

El objetivo perseguido con este tipo de contratos, es incorporar al INFOCOOP como asociado de organismos cooperativos, para dotarlos de recursos de capital, lograr su fortalecimiento y el desarrollo a través de la ejecución de proyectos que guarden armonía con los objetivos y fines institucionales, favorecer a poblaciones de escasos recursos, la generación o mantenimiento y creación de puestos de trabajo, con modelos de gestión basados en los valores cooperativos, que permitan desarrollar el capital humano y social tal que por su impacto regional o nacional -artículo 2-.

Una vez firmado el contrato de Participación Asociativa - artículo 23-, el INFOCOOP adquiere varios derechos que restringen la autonomía e independencia de la cooperativa con la injerencia del INFOCOOP dentro de la estructura política de la cooperativa, pues se deberán hacer las modificaciones estatutarias para regular la participación de los representantes del Instituto, en la Asamblea por medio de delegados nombrados por el mismo, la participación de representantes del Instituto en el seno del Consejo de Administración, derecho a voz y voto en el seno de ese órgano, y se requiere de su voto favorable para la aprobación de los acuerdos definidos en el contrato de participación asociativa. Dicho voto deberá quedar debidamente justificado —artículo 10-.

Durante la vigencia del contrato, los representantes del INFOCOOP podrán vetar razonadamente el nombramiento y remoción del gerente 
del organismo cooperativo o bien participar en el proceso de selección. Además, podrán solicitar que se establezca la estructura de control requerida para asegurar el logro de los objetivos del proyecto, la salvaguarda y reembolso de los recursos públicos invertidos - artículo 12-, la emisión de certificados de participación que reflejen el monto de los recursos económicos entregados al ente cooperativo -artículo 15así como reformas relacionadas con los mecanismos de control en la participación asociativa, con el objetivo de fiscalizar el uso y aplicación de los recursos públicos otorgados, la recuperación de éstos, así como la buena marcha del proyecto, el reconocimiento al INFOCOOP de la facultad de nombrar contralores, administradores, fiscalizadores $u$ otros mecanismos que incidan en el logro de los objetivos de los proyectos apoyados, su adecuada gestión, de los recursos otorgados al Organismo Cooperativo -artículo 23-.

También, dentro del contrato se debe incorporar la disposición de los excedentes - ganancias - cuando el ente cooperativo no tuviera efectivo, depositando el $60 \%$ de los mismos en una reserva, para retornar al INFOCOOP - art. 17- el monto total o parcial de los recursos entregados.

\section{Restricciones al principio de autonomía cooperativa por leyes posteriores e invasión de competencias propias de las cooperativas de intermediación financiera a través de normas de rango inferior. El caso del reglamento de gobierno corporativo-SUGEF 16-16}

Desde 1994 se promulgó la Ley de Regulación de la Actividad de Intermediación Financiera de las Organizaciones Cooperativas, Ley 7391, se les sometió al control de entes de supervisión financiera nacional, fuera del control y supervisión del INFOCOOP. El párrafo segundo del artículo 119 de la Ley Orgánica del Banco Central de Costa Rica, Ley 7558, establece que, en relación con la operación propia de las entidades fiscalizadas por la Superintendencia de entidades financieras (SUGEF), se podrán dictar las normas generales que sean necesarias para el establecimiento de sanas prácticas bancarias, todo en salvaguarda del interés de la colectividad.

En el 2016, por acuerdo del Consejo Nacional de Supervisión del Sistema Financiero (CONASSIF) se emitió el Reglamento de Gobierno Corporativo SUGEF 16-16, y se introdujeron varias directrices al sector económico-financiero, donde las cooperativas de ese giro comercial, forman parte, y les obliga a cambiar la integración de sus cuerpos di- 
rectivos, para las cooperativas de su Consejo de Administración y otros comités:

Respecto de la Composición y Perfil del Órgano de Dirección se establece, en el Reglamento, la incorporación al Consejo de Administración de al menos dos directores independientes, con voz y voto, y se extiende su participación a los comités existentes —artículos 16, 25, 26, 27 y 28-. Entendiéndose como Director independiente un ente externo a la cooperativa.

Al respecto, algunas cooperativas del sector financiero se han opuesto, como se puede ver del análisis del INFOCOOP, según comunicación a la Dirección Ejecutiva SC-711-22-2017. Tales cooperativas parten de la consideración de que si bien, la LAC no dispone, expresamente, que el Consejo de Administración solo puede estar integrado por asociados(as), no existe una delegación que permita regular por reglamento, una integración de esos órganos sociales en diferente forma e impidiendo la elección libre y democrática basada en la ley cooperativa, por ejemplo artículo 34, inciso d, relacionado con los deberes y derechos de los miembros asociados, entre los cuales estaría la decisión de permitir que la integración de los órganos sociales, debe ser únicamente con asociados de la organización cooperativa.

También, se ha resaltado, por parte de las cooperativas consultantes del INFOCOOP, la posible contraposición entre el Reglamento en análisis y la LAC, sobre la responsabilidad de los miembros del Consejo de Administración y el Comité de Vigilancia —artículos 49 y 52 que les otorga una responsabilidad solidaria, mientras que al Director independiente, se le exime de toda responsabilidad de gestión y asesoría en la entidad o grupo o conglomerado financiero en el que participen -artículo 3, inciso j)-.

En cuanto al INFOCOOP, este ente considera que existen bases internacionales y nacionales que fundamentan los nombramientos, citan el artículo 61 del Proyecto de Ley Marco para las Cooperativas de América Latina, avalado por la Alianza Cooperativa Internacional $(\mathrm{ACl})$, que establece la integración del Consejo de administración en cuanto al número, determinado por el Estatuto, pero no prohíbe la integración de miembros externos a la cooperativa. Además, por ser cooperativas, considera que no les exime de ninguna manera de cumplir la regulación estatal, en materia de intermediación financiera por parte de las autoridades competentes, esencialmente la LAC —artículo 21-, Ley de Regulación de la Actividad de Intermediación Financiera de las Organizaciones Cooperativas —artículo 7-y la Ley Orgánica del Banco Central de Costa Rica artículo 117. Y dado que el límite del artículo 4 de la LAC se refiere a restricciones legales, concluye el Instituto, que no 
se cuenta con el respaldo legal necesario para oponerse a dicha medida establecida en ese Reglamento SUGEF 16-16. También el criterio emitido por el INFOCOOP contempló la forma de nombramiento de los Directores Independientes, y hace referencia a oficio recibido en la institución, número SGF-1315-2017, que aclara el procedimiento de elección de tales miembros, a través de la Asamblea de la cooperativa, sea ésta de asociados o de delegados, o bien deja la posibilidad de delegar su designación en un órgano social de la cooperativa, de acuerdo con sus lineamientos, lo cual en opinión del Instituto, es conforme al principio de control democrático.

\section{Conclusiones generales}

En Costa Rica el Principio de Autonomía e independencia no está formulado expresamente en la LAC, sin embargo, si hay consciencia en los entes públicos relacionados con las cooperativas, sobre todo en el INFOCOOP y la PGR acerca de su importancia y el respeto que se debe a las cooperativas, en el tanto que ese principio forma parte de su identidad.

Al momento, no hay conciencia en el Cooperativismo nacional sobre los alcances del Principio de Autonomía, por lo cual no ha sido aprovechado en la defensa de los derechos de las cooperativas y sus miembros. Como ejemplo, no se esgrimió su existencia frente a los diputados y miembros de los Supremos Poderes, cuando se trató de imponer nuevos impuestos a las cooperativas, tal y como lo manifestaron algunos de los entrevistados.

Cuando a las cooperativas costarricenses se les presentan oportunidades de nuevos negocios, o bien la posibilidad de incursionar en sectores no experimentados, que pueden ser servicios públicos como la salud, transporte, o bien, actividades muy reguladas por el Estado como comercialización internacional del café o intermediación financiera, entre otros, tienen que considerar los límites a su autonomía que implican los acuerdos o las leyes dictadas para todo el sector elegido.

El cooperativismo costarricense debe avocarse a realizar un mayor análisis y discusión de los Principios cooperativos, su valor y su relación con los valores, e incorporarlos para aprovecharlos como escudo, en defensa de su propia identidad y el principio de autonomía no es una excepción, pues no ha sido asimilado más allá de los casos concretos que en alguna medida se han hecho conocer a través de este análisis. 


\section{Glosario}

Instituto Nacional de Fomento Cooperativo

INFOCOOP

Caja Costarricense de Seguro Social

CCSS

Consejo Nacional de Supervisión del Sistema Financiero

CONASSIF

Ley de Asociaciones Cooperativas

Ministerio de Trabajo y Seguridad Social

LAC

Procuraduría General de la República

MTSS

PGR

\section{Bibliografía}

AKE, S. 1992. Valores cooperativos para un mundo en cambio. Informe para el XXX Congreso de la ACl, Tokio, octubre de 1992. San José: Ed. Oficina Regional para Centro América y el Caribe de $\mathrm{ACl}$.

ALIANZA COOPERATIVA INTERNACIONAL. 2015. Notas de orientación para los principios cooperativos. Alianza Cooperativa Internacional.

COLÓN, R. 2018. «La ruta autodestructiva del cooperativismo de vivienda puertorriqueño: el problema de la pérdida de la identidad cooperativa mediante la transformación de valores de uso en valores de cambio». Boletín Asociación Internacional de Derecho Cooperativo, 52: 19-46. doi: http:// dx.doi.org/10.18543/baidc-52-2018pp19-46

EGUÍA, F. y MACPHERSON, I. 1997. Identidad Cooperativa. México: Ed. Alianza Cooperativa Internacional.

GADEA, E., SACRISTÁN, F. y VARGAS, C. 2009. Régimen jurídico de la sociedad cooperativa del siglo XXI. Realidad actual y propuestas de reforma. Madrid: Ed. Dykinson S.L.

GÓMEZ, L. y MARTíNEZ, A. 1999. "Origen y alcance del principio de autonomía e independencia de las Cooperativas». Boletín Asociación Internacional de Derecho Cooperativo, vol. II, No. 33: 25-40.

SÁNCHEZ, R. 2018. "La participación económica de los socios cooperativos: cooperativas tradicionales, autogestionarias y cogestionarias de Costa Rica». Boletín Asociación Internacional de Derecho Cooperativo, 53: 3765. doi: http://dx.doi.org/10.18543/baidc-53-2018pp37-65

Leyes, reglamentos, dictámenes y consultas

ASAMBLEA LEGISLATIVA (1965). Ley N. N. 3579. Ley de la Agricultura e Industria de la Caña de Azúcar. Recuperado el 30 de abril de 2019 de https:// aresep.go.cr/images/documentos/Ley\%20Generacion\%20Electrica\%20 Autonoma\%200\%20Paralela.pdf

ASAMBLEA LEGISLATIVA (1990). Ley que Autoriza la Generación Eléctrica Autónoma o Paralela, Ley N. 7200 de 28 de septiembre de 1990. Recuperado el 30 de abril de 2019 de http://www.pgrweb.go.cr/scij/ 
Busqueda/Normativa/Normas/nrm_texto_completo.aspx?param1=NRTC\&n Valor1=1\&nValor2=7591\&nValor3=8139\&strTipM=TC

ASAMBLEA LEGISLATIVA (1994). Ley de intermediación financiera de cooperativas de ahorro y crédito N. 7391. Recuperado el 28 mayo de 2018 de http://www.pgrweb.go.cr/scij/Busqueda/Normativa/Normas/nrm texto_completo.aspx? param $1=$ NRTC \&nValor $1=1 \&$ nValor $2=11935 \& \mathrm{n}$ Valor3=93291\&strTipM=TC

ASAMBLEA LEGISLATIVA (1998). Ley N. 7852 Ley de desconcentración de los hospitales y las clínicas. La Gaceta N. ${ }^{\circ} 250$ del 24 de diciembre de 1998. San José, Costa Rica. Recuperado el 12 de abril de 2019 de http://www. siprocimeca.com/Downloads/Documentos \%20legales/Leyes/LEY\%20 DE \%20DESCONCENTRACION\%20DE \% 20LOS \% 20HOSPITALES \% 20 Y\%20LAS\%20CLINICAS.pdf

ASAMBLEA LEGISLATIVA (2003). Ley N. ${ }^{\circ} 8345$, Participación de las Cooperativas de Electrificación Rural y de las Empresas de Servicios Públicos Municipales en el Desarrollo Nacional. Recuperado el 30 de abril de 2019 de http://www.pgrweb.go.cr/scij/Busqueda/Normativa/Normas/ nrm_texto_completo.aspx?param $1=$ NRTC\&nValor $1=1 \&$ nValor $2=50204 \&$ n Valor3=73659\&strTipM=TC

CONELECTRICAS, R.L. (2019). Quienes somos. Recuperado el 25 de mayo de 2019 de http://www.conelectricas.com/quienes-somos/

CONSEJO NACIONAL DE SUPERVISIÓN DEL SISTEMA FINANCIERO (2016). Acuerdo SUGEF 16-16, Reglamento sobre gobierno corporativo. Recuperado el 30 de abril de 2016 de https://www.sugef.fi.cr/normativa/ normativa_vigente/documentos/SUGEF\%2016-16\%20(v_02\%20\%20 diciembre\%202016).pdf

COOPESALUD, R.L. (2019). Historia de COOPESALUD y otros servicios. ¿Quiénes Somos? Recuperado el 3 de abril de 2019 de http://servisaludcr.com/nosotros/

INSTITUTO NACIONAL DE FOMENTO COOPERATIVO (2004 y 2010). DictámenesMGS-443-2004 del 6 de julio de 2004 y MGS-976-691-20 10 de 1 de octubre del 2010. Recuperados el 29 de abril de 2019 de http://www.infocoop.go.cr/nuestros_servicios/supervision/jurisprudencia/ 6PersonasMGS-976-691-2010.pdfhttp://www.infocoop.go.cr/nuestros_ servicios/supervision/jurisprudencia/6PersonasMGS-1194-2005.pdf

INSTITUTO NACIONAL DE FOMENTO COOPERATIVO (2010). MGS-234-6132010, de 11 de marzo del 2010. Recuperado el 29 de abril de 2019 de http://www.infocoop.go.cr/nuestros_servicios/supervision/jurisprudencia/1 ConsejoMGS-234-613-2010.pdf

INSTITUTO NACIONAL DE FOMENTO COOPERATIVO (2015). SC-592-2015 de 23 de junio de 2015. Recuperado el 29 de abril de 2019 de http://www. infocoop.go.cr/nuestros_servicios/supervision/jurisprudencia/SC \%205922015.pdf.

INSTITUTO NACIONAL DE FOMENTO COOPERATIVO (2017). Dictamen SC711-22-2017. Recuperado el 30 de abril de 2019 de http://www.pgrweb. go.cr/scij/Busqueda/Normativa/pronunciamiento/pro_ficha.. aspx?param 1=P RD\&param6=1\&nDictamen $=7971 \&$ strTipM $=$ T 
PROCURADURÍA GENERAL DE LA REPÚBLICA (2006). Dictamen C-490-2006 de 12 de diciembre de 2006. Recuperado el 25 de abril de 2019 de http:// www.pgrweb.go.cr/scij/Busqueda/Normativa/pronunciamiento/pro_ficha. aspx? param 1=PRD\&param6=1\&nDictamen $=14302 \&$ strTipM $=T$

PROCURADURÍA GENERAL DE LA REPÚBLICA (2010). Pronunciamiento C-0622010 de 12 de abril de 2010. Recuperado el 30 de mayo de 2019 de http://www.pgrweb.go.cr/scij/Busqueda/Normativa/pronunciamiento/pro_ ficha. aspx? param1 $=$ PRD\&param6 $=1 \&$ nDictamen $=16963 \&$ strTipM $=T$

PROCURADURÍA GENERAL DE LA REPÚBLICA (2013). Pronunciamiento C-0192013 de13 de febrero de 2013. Recuperado 25 de abril de 2019 http:// www.pgrweb.go.cr/scij/Busqueda/Normativa/pronunciamiento/pro_ficha. aspx? param1=PRD\&param6=1\&nDictamen $=17493 \&$ strTipM $=T$

RECIO, P. (2015). CCSS amplía por cuatro años contrato con cooperativas de Salud. LA NACION en línea. Recuperado el 2 de abril 2019 de https:// www.nacion.com/el-pais/salud/ccss-amplia-por-cuatro-anos-contrato-concooperativas-de-salud/FSUWUQYUV5B4NOVUKIP6XUYWBU/story/ /

\section{Anexo}

ENTREVISTA REALIZADA A FECHA LUGAR

FINES DE LA ENTREVISTA: busca recabar información de tipo cualitativo, con base en la Teoría Fundamentada para definir el ejercicio práctico del PRINCIPIO DE AUTONOMÍA E INDEPENDENCIA COOPERATIVA EN COSTA RICA. Esa información será parte de la contribución anual de la Dra. Ligia Roxana Sánchez Boza al Boletín de la Asociación Internacional de Derecho Cooperativo, con sede en la Universidad de Deusto, Bilbao, España.

TEXTO DEL PRINCIPIO DE AUTONOMÍA E INDEPENDENCIA: «LaS cooperativas son sociedades autónomas de ayuda mutua gestionadas por sus propios miembros. Cuando firman acuerdos con otras organizaciones, incluyendo los gobiernos, o consiguen capital de fuentes externas, lo hacen asegurando el autogobierno de los socios y afianzando la autonomía de la cooperativa.»

1. ¿Se podría considerar que este principio es una pared frente a la intervención externa: estatal o de un ente externo relacionado con la actividad económica de las cooperativas?

2. ¿Sería o es sana la intervención de terceros como socios capitalistas, cuando se requieren recursos económicos para impulsar el desarrollo de la cooperativa? ¿Por ejemplo: bancos estatales 
o privados, pensionados o interesados únicamente en mantener depósitos a plazo para obtener mayores ganancias en los intereses generados?

3. ¿Es posible establecer los alcances y límites de la autonomía e independencia de las cooperativas?

4. ¿Se podría considerar la gobernanza impuesta por los entes financieros: internos y externos a Costa Rica un límite a las cooperativas de intermediación financiera?

5. Algunos autores indican que las cooperativas no dependen de nadie, como sociedad o empresa, sino que se gobiernan por sus propios socios.

Frente a esa opinión, encuentra usted alguna contradicción con la actividad de control y supervisión ejercida por el INFOCOOP, o de otros entes que les imponen cargas para desarrollar su giro económico. Podría mencionar dos o tres.

6. ¿Conoce los antecedentes de la introducción de este principio cooperativo?

7. ¿En Costa Rica ha contribuido la existencia del Principio mencionado, frente a las diferentes acciones de diputados y otros miembros del Gobierno actual que pretenden gravar los excedentes de las cooperativas?

8. ¿Gusta agregar algo más al respecto?

Gracias por su colaboración. 


\section{Derechos de autor}

El Boletín de la Asociación Internacional de Derecho Cooperativo es una revista de acceso abierto lo que significa que es de libre acceso en su integridad inmediatamente después de la publicación de cada número. Se permite su lectura, la búsqueda, descarga, distribución y reutilización legal en cualquier tipo de soporte sólo para fines no comerciales y según lo previsto por la ley; sin la previa autorización de la Editorial (Universidad de Deusto) o el autor, siempre que la obra original sea debidamente citada (número, año, páginas y DOI si procede) y cualquier cambio en el original esté claramente indicado.

\section{Copyright}

The International Association of Cooperative Law Journal is an Open Access journal which means that it is free for full and immediate access, reading, search, download, distribution, and lawful reuse in any medium only for non-commercial purposes, without prior permission from the Publisher or the author; provided the original work is properly cited and any changes to the original are clearly indicated. 